\title{
Eine vereinfachte Modifikation der Hydroxamatmethode zur Bestimmung der Cholinesteraseaktivität im Blut
}

\author{
Von H. Willgerodt, H. Theile und K. Beyreiss \\ Aus der Kinderklinile der Universität Leipzig (Direktor: Prof. Dr. med. S. Liebe)
}

(Eingegangen am 11. Januar 1968)

\begin{abstract}
Beschreibung einer vereinfachten Modifikation der Hydroxamatmethode zur Bestimmung der Cholinesteraseaktivität im Serum. Das Verfahren ist zur Anwendung im klinischen Routinebetrieb geeignet. Die erforderliche Serummenge beträgt $25 \mathrm{bzw}$. $50 \mu l$. Als Substrat wird Acetylcholin verwendet. Die Normalwerte bei 50 gesunden Blutspendern betragen $3470 \pm 600$ IU/l. Der relative Fehler der Methode beträgt 3,2\%. Das Verfahren beruht auf der Bildung eines rötlich-braunen Komplexes aus $\mathrm{Fe}^{+++}$-Ionen und Acetylhydroxamsäure mit einem breiten Absorptionsmaximum bei $490 \mathrm{~nm}$. Zur praktischen Durchführung der Bestimmung sind lediglich ein thermokonstantes Wasserbad von $37^{\circ}$ und ein Photometer bzw. Kolorimeter, das Ablesungen bei $490 \mathrm{~nm}$ gestattet, notwendig.
\end{abstract}

A method is described for the determination of serum cholinesterase activity by a simplified modification of the hydroxamate method. The method is suitable for routine determinations in the clinical laboratory. 25 or $50 \mu l$ of serum are required. Acetyl choline is used as the substrate. The normal value determined in 50 healthy blood donors was $3470 \pm 600 \mathrm{IU} / \mathrm{l}$. The relative error of the method is $3.2 \%$. The method is based on the formation of a red-brown complex (absorption maximum $490 \mathrm{~nm}$ ) between Fe $\mathrm{F}^{+++}$ions and acetylhydroxamic acid. A constant temperature water bath at $37^{\circ}$ and a photometer or colorimeter for measurements at $490 \mathrm{~nm}$ are required.

Im Gegensatz zu der früher häufig geäußerten Zurückhaltung wird die Bedeutung der Cholinesteraseaktivität ${ }^{1}$ ) des Serums für die Beurteilung der Leberfunktion und die Diagnostik und Verlaufskontrolle verschiedener Erkrankungen der Leber durch zahlreiche neuere Mitteilungen $(1,2,3)$ unterstrichen. Von besonderem Wert ist die Bestimmung der Cholinesteraseaktivität bei chronischen Leberparenchymschäden und degenerativen Erkrankungen der Leber, während die Aktivität der Serumtransaminasen hier von geringer Aussagekraft ist. Auch für die Feststellung von Vergiftungen mit organischen Phosphorsäureestern, die in zahlreichen modernen Pflanzenschutzmitteln enthalten sind, ist die $\mathrm{Be}$ stimmung der Cholinesteraseaktivität des Serums unerläßlich.

Die zahlreichen Methoden zur Bestimmung cholinesterspaltender Enzyme lassen sich in zwei große Gruppen einteilen. Zur ersten Gruppe gehören Methoden wie das manometrische Verfahren von AMMON (4) und die automatische elektrometrische Titration, mit denen die Kinetik der Spaltung gut verfolgt werden kann. Sie sind die empfindlichsten und zugleich exaktesten bisher - bekannten Methoden. Im klinischen Routinebetrieb konnten sich diese Methoden wegen des beträchtlichen zeitlichen und technischen Aufwandes aber nicht durchsetzen.

Bei der zweiten Gruppe von Verfahren handelt es sich im wesentlichen darum, das innerhalb einer bestimmten Zeitspanne nicht umgesetzte Substrat zu bestimmen. Das kann direkt geschehen durch Messung der nicht gespaltenen Cholinester in Form ihrer Eisenhydroxamate oder im Falle des Benzoylcholins, das ein spezifisches Absorptionsmaximum bei $240 \mathrm{~nm}$ besitzt, spektrophotometrisch nach Karow (5), wobei die Extinktionsabnahme bei der enzymatischen Spaltung von Benzoylcholin registriert wird. Andere Verfahren verfolgen die bei der Hydrolyse von Acetylcholin freigesetzte Essigsäure durch direkte Messung der pH-Änderung am Ende

\footnotetext{
1) Der Trivialname Cholinesterase wird hier gebraucht für das
} Enzym Acetylcholin-Acetylhydrolase (EC 3.1.1.7). der Einwirkungszeit des Enzyms, was ein empfindliches $\mathrm{pH}-\mathrm{Meßgerät}$ voraussetzt, da $z$. B. bei der von MEINECKE und Oetrel (6) kürzlich publizierten Mikromethode der Normalwert im Serum einer $\mathrm{pH}$-Änderung von nur $0,74 \mathrm{pH}-$ Einheiten/Std. entspricht.

Die auch von uns verwendete Hydroxamatmethode wurde erstmals von Hestrin (7) zur Bestimmung der Cholinesteraseaktivität verwendet. Es ist das besondere Verdienst von Pilz (8), die genauen analytischen Grundlagen dieser Methode erarbeitet $z u$ haben, die darauf beruht, daß sich im alkalischen Milieu Carbonsäureester mit Hydroxylamin zu Hydroxamsäuren umsetzen, die mit $\mathrm{Fe}^{+++}$-Ionen rötlich gefärbte Verbindungen liefern. Die von PIlz (9) angegebene und mehrfach modifizierte Arbeitsvorschrift, deren Anwendung nach Angaben des Autors und anderer Untersucher (2) bei exaktem Arbeiten sehr genaue Resultate liefert, hat sich aber zumindest als Routinemethode in der Klinik nicht durchsetzen können, was offenbar durch den erheblichen Aufwand an Zeit und Arbeit zu erklären ist. Wir haben deshalb versucht, die Hydroxamatmethode weiter $z u$ vereinfachen mit dem Ziel, die Anwendung dieses sehr genauen Verfahrens auch im klinischen Routinelabor zu ermöglichen.

\section{Methodik}

Prinzip:

Hydroxylamin reagiert in alkalischer Lösung mit Acetylcholin unter Bildung von Acetylhydroxamsäure und Cholin. Acetylhydroxamsäure bildet mit $\mathrm{Fe}^{+++}$eine rötlich-braune Verbindung mit einem breiten Absorptionsmaximum bei $490 \mathrm{~nm}$. Zur Bestimmung der Cholinesteraseaktivität des Serums wird die Substratkonzentration am Anfang und nach beendeter Inkubation mit Serum oder Plasma gemessen.

\section{Reagentien}

1. Tris-Puffer $\mathrm{pH} 7,4,0,2 \mathrm{M}: 24,3 \mathrm{~g}$ Tris $\cdot \mathrm{HCl}$ mit bidest. Wasser ad $1000 \mathrm{~m} l$ auffüllen. $25 \mathrm{~m} /$ dieser Stammlösung und $42 \mathrm{~m} / 0,1 \mathrm{~N}$ $\mathrm{HCl}$ mit bidest. Wasser ad $100 \mathrm{~m} /$ auffüllen. Bei $4^{\circ}$ mehrere Monate haltbar.

2. $2,5 \mathrm{~N} \mathrm{NaOH}$ : $50 \mathrm{~g} \mathrm{NaOH}$ p. a. in Plätzchenform mit bidest. Wasser ad $500 \mathrm{ml}$ auffüllen. 
3. Hydroxylamin-Stammlösung, 7 proz.: $35 \mathrm{~g}$ Hydroxylamin $\cdot \mathrm{HCl}$ mit dest. Wasser ad $500 \mathrm{~m} /$ auffüllen. Nur 14 Tage haltbar.

4. Alkalische Hydroxylamin-Gebrauchslösung. Unmittelbar vor Benutzung herzustellen: Lösung 2 und Lösung 3 werden zu gleichen Teilen gemischt.

5. $0,67 \mathrm{M} \mathrm{FeCl}_{3}$-Lösung: $188,9 \mathrm{~g} \mathrm{FeCl}_{3} \cdot 6 \mathrm{H}_{2} \mathrm{O}$, (Union Chimique Belge) in etwa $500 \mathrm{~m} /$ bidest. Wasser lösen und $10 \mathrm{~g} \mathrm{KNO}_{3} \mathrm{zu}-$ geben. Nach Auflösung des $\mathrm{KNO}_{3}$ mit bidest. Wasser ad $1000 \mathrm{ml}$ auffüllen. Die Lösung ist mehrere Monate bei Zimmertemperatur haltbar.

6. $2 \mathrm{~N} \mathrm{HCl}: 180 \mathrm{~m} /$ konz. $\mathrm{HCl}(\mathrm{D}=1,19)$ mit dest. Wasser ad $1000 \mathrm{~m} /$ auffüllen.

7. Acetylcholinsubstratlösung, $9,6 \mathrm{~mm}$ : $174,3 \mathrm{mg}$ Acetylcholinchlorid mit bidest. Wasser ad $100 \mathrm{~m} /$ lösen und mit wenigen Tropfen $2 \mathrm{~N}$ Essigsäure auf $\mathrm{pH} 4-5$ einstellen. Alle 14 Tage frisch herstellen.

8. $\mathrm{NaCl}$-Lösung 0,9 proz.

\section{Glasgeräte}

Blutzuckerpipetten für $50 \mu l$ Serum, $0,5 \mathrm{~m} /$ Vollpipetten, $1,0 \mathrm{ml}$ Vollpipetten, $1,0 \mathrm{~m} l$ Stabpipetten, $10 \mathrm{~m} /$ Stabpipetten, Reagenzgläser.

Thermokonstantes Wasserbad von $37^{\circ}$, Photometer z. B. „Spekol“" VEB Carl Zeiß, Jena, oder Kolorimeter.

\section{Arbeitsvorscbrift}

Ansetzen eines Reagenzienleerwertes, eines Haupt- und eines Blindwertes. Erforderliche Serum- oder Plasmamenge $50 \mathrm{bzw}$. $25 \mu l$. Die einzelnen Lösungen werden, wie aus dem folgenden Schema ersichtlich ist (Tab. 1), in Reagenzgläser pipettiert.

Tab. 1

Arbeitsschema für die Bestimmung der Cholinesteraseaktivität

\begin{tabular}{|c|c|c|}
\hline Reagenzien-Leerwert & Blindwert & Hauptwert \\
\hline $\begin{array}{c}1,0 \mathrm{ml} \text { Trispuffer } \\
2,15 \mathrm{ml} 0,9 \text { proz. } \mathrm{NaCl} \\
-\end{array}$ & $\begin{array}{c}1,0 \mathrm{ml} \text { Trispuffer } \\
1,15 \mathrm{ml} 0,9 \mathrm{proz} \text {. NaCl } \\
1,0 \mathrm{ml} \text { Acetylcholin- } \\
\text { Substratlösung }\end{array}$ & $\begin{array}{c}1,0 \mathrm{ml} \text { Trispuffer } \\
1,15 \mathrm{ml} \mathrm{0,9proz.} \mathrm{NaCl} \\
1,0 \mathrm{ml} \text { Acetylcholin- } \\
\text { Substratlösung } \\
50 \mu l \text { Serum oder } \\
\text { Plasma }\end{array}$ \\
\hline
\end{tabular}

20 Min. bei $37^{\circ}$ im Wasserbad inkubieren, mehrmals vorsichtig umschütteln

\begin{tabular}{|c|c|c|}
\hline $\begin{array}{c}0,5 \mathrm{ml} \text { alkalisches } \\
\text { Hydroxylamin } \\
50 \mu l \text { Serum oder } \\
\text { Plasma }\end{array}$ & $\begin{array}{c}0,5 \mathrm{ml} \text { alkalisches } \\
\text { Hydroxylamin } \\
50 \text { pl Serum oder } \\
\text { Plasma }\end{array}$ & $\begin{array}{c}0,5 \mathrm{ml} \text { alkalisches } \\
\text { Hydroxylamin }\end{array}$ \\
\hline \multicolumn{3}{|c|}{10 Min. bei Zimmertemperatur stehenlassen } \\
\hline $\begin{array}{c}0,3 \mathrm{ml} 2 \mathrm{~N} \mathrm{HCl} \\
1,0 \mathrm{ml} \mathrm{FeCl}_{3}\end{array}$ & $\begin{array}{l}0,3 \mathrm{ml} 2 \mathrm{~N} \mathrm{HCl} \\
1,0 \mathrm{ml} \mathrm{FeCl}_{3}\end{array}$ & $\begin{array}{c}0,3 \mathrm{ml} 2 \mathrm{~N} \mathrm{HCl} \\
1,0 \mathrm{ml} \mathrm{FeCl} l_{3}\end{array}$ \\
\hline \multicolumn{3}{|c|}{30 Min. bei Zimmertemperatur stehenlassen } \\
\hline
\end{tabular}

Anschließend werden zu jedem Röhrchen $10 \mathrm{~m} /$ bidest. Wasser gegeben und vorsichtig durchgeschüttelt (zu starkes Schäumen vermeiden). Die Extinktionen von Hauptwert und Blindwert verden innerhalb der nächsten $2 \mathrm{Stdn}$. bei $490 \mathrm{~nm}$ und $1 \mathrm{~cm}$ Schichtdicke gegen den Reagenzienleerwert abgelesen.

\section{Bereclonung}

Die Änderungen der Acetylcholinkonzentration werden aus einer Eichkurve abgelesen. Beim Aufstellen der Eichkurve geht man ebenso vor, wie für die Hauptversuche beschrieben, d. h. entsprechende Teile einer Lösung von Acetylcholinchlorid werden mit $\mathrm{NaCl}$, Trispuffer, Hydroxylamin, $2 \mathrm{~N} \mathrm{HCl}$ und $\mathrm{FeCl}_{3}$-Lösung versetzt und die Farbentwicklung abgewartet. Danach gibt man zu jedem der $5,0 \mathrm{~m} /$ betragenden Ansätze $10 \mathrm{~m} l$ bidest. Wasser, schüttelt gut um und mißt die Extinktion bei $490 \mathrm{~nm}$ und $1 \mathrm{~cm}$ Schichtdicke in Glasküvetten gegen den Reagenzienleerwert. Für den Routinebetrieb genügt eine Eichkurve im Konzentrationsbereich von 0,08 bis $1,2 \mu \mathrm{Mol}$ Acetylcholin pro $1,0 \mathrm{ml}$ im Meßansatz, wobei zu beachten ist, daß das ursprüngliche Volumen von $5,0 \mathrm{~m} /$ vor dem Ableșen der Extinktion durch Zugabe von Wasser auf $15 \mathrm{ml}$ erhöht wird (s. o.). Diese Verdünnung ist bei den Ansätzen zur Farbentwicklung zu berücksichtigen, die deshalb mit der 3 fachen Konzentration an Acetylcholin anzusetzen sind, verglichen mit dem endgültigen Ansatz zur Registrierung der Extinktion.

Zur Berechnung der Acetylcholinesteraseaktivität wird die Acetylcholinkonzentration des Blindwertes $\mathrm{E}_{1}, \mathrm{~d}$. h. die Konzentration vor Beginn der Inkubation, aus der Eichkurve ermittelt und von dieser die Konzentration des Hauptwertes $E_{2}$, d. h. die nach beendeter Inkubation noch vorhandene Konzentration in $\mu \mathrm{Mol} / \mathrm{ml}$ Acetylcholin subtrahiert. Man erhält so den Umsatz des Substrates als $\Delta \mu \mathrm{Mol} / \mathrm{m} /$. Hieraus kann nach der Formel

$$
\Delta \mu \mathrm{Mol} / \mathrm{ml} \cdot 15000=\mathrm{IU} / l
$$

die Acetylcholinesteraseaktivität berechnet werden, wobei eine $\mathrm{IU} / l$ den Substratumsatz von $1 \mu \mathrm{Mol}$ in einer Minute durch $1000 \mathrm{~m} l$ Serum bei $37^{\circ}$ bedeutet.

Ableitung der Formel (1)

$$
\begin{gathered}
\Delta \mu \mathrm{Mol} / \mathrm{m} l \triangleq \Delta \mathrm{E} \\
\Delta \mathrm{E}=\mathrm{E}_{1}-\mathrm{E}_{2} \\
\frac{\Delta \mu \mathrm{Mol} / \mathrm{m} l \cdot 15 \cdot 20000}{20}=\Delta \mu \mathrm{Mol} / \mathrm{m} l \cdot 15000=\mathrm{IU}
\end{gathered}
$$

In Gleichung (4) entsteht der Faktor 15, da von der aus der Eichkurve ermittelten Konzentrationsabnahme in $\mu \mathrm{Mol}$ pro $1,0 \mathrm{ml}$ auf das Gesamtvolumen des Ansatzes von $15 \mathrm{~m} /$ zu beziehen ist, der Faktor 20000 , da $50 \mu l$ Serum verwendet wurden und auf $1000 \mathrm{ml}$ zu beziehen ist. Mit 20 ist zu dividieren, da die Enzymeinheit auf $1 \mathrm{Min}$. bezogen wird.

Für die praktische Durchführung ist es nicht erforderlich, für jede Serumprobe einen eigenen Reagenzienleerwert anzusetzen. Es genügt, einen einzigen Leerwert mit einem beliebigen klaten, durch vorherigen Hydroxylaminzusatz inaktivierten Serum anzusetzen, gegen den alle übrigen Werte abgelesen werden.

\section{Reaktionsbedingungen}

Die in Abbildung 1 dargestellte Eichkurve zeigt einen linearen Verlauf. Für die verwendeten Konzentrationen bis $1,2 \mu \mathrm{Mol}$ Acetylcholin $/ \mathrm{m} l$ ist das LAMBERT-BeErsche Gesetz erfüllt. Die Gerade verläuft durch den Nullpunkt. Zahlreiche mit verschiedenen Reagenzien angefertigte Eichkurven zeigten eine sehr gute Übereinstimmung. (Es wurden z. B. $\mathrm{FeCl}_{3}$ der Firmen Riedel de Haën, Reanal Budapest und der Union Chimique Belge geprüft.) Die von Meinecke und Oetrer (6) bei dem Verfahren von Przz (9) gefundene Instabilität des Eisenreagenz wurde dabei von uns nicht beobachtet. Durch Zusatz von Serum nach dem Hydroxylamin entsprechend dem Blindwert wird der Verlauf der Eichkurve nur unwesentlich beeinflußt und bleibt streng linear. In Abbildung 2 ist der Einfluß der Substratkonzentration auf die Aktivität der Cholinesterase dargestellt. Die Abbildung zeigt eine typische Sättigungskinetik entsprechend der Michaelis-Menten-Hypothese. Bis zu einer Substratkonzentration von $10 \mu \mathrm{Mol} / \mathrm{m} l$ im Inkubationsansatz tritt keine Hemmung der Acetylcholinesteraseaktivität des Serums auf. Für die angegebene Routinemethode wählten wir eine Substratkonzentration von $3 \mathrm{~mm}$.

Abbildung 3 zeigt die Abhängigkeit des Substratumsatzes von der Enzymmenge. Zur Untersuchung der Beziehung zwischen eingesetzter Enzymmenge und 


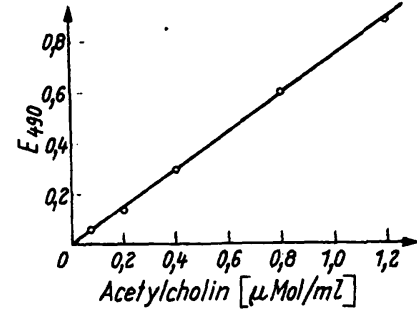

Abb, 1

Eichkurve für Acetylcholin. Reaktionsbedingungen: Tris-Puffer $\mathrm{pH} 7,4$, Endkonzentration $62 \mathrm{mM}$, Acetylcholinchlorid entsprechend den in der Abszisse angegebenen Endkonzentrationen, 0,9 proz. $\mathrm{NaCl}$ ad $3,15 \mathrm{ml}$ $0,5 \mathrm{ml}$ alkalisches Hydroxylamin, danach $0,05 \mathrm{ml}$ Serum

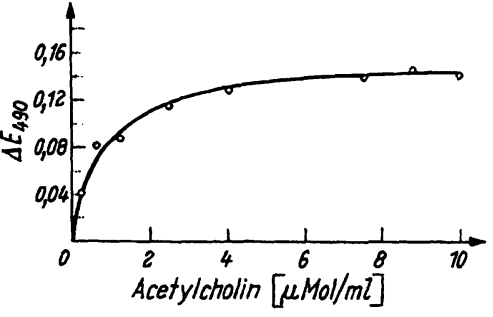

Abb. 2

Einfluß der Substratkonzentration auf die Enzymaktivität. $1,0 \mathrm{~m} /$ Tris (pH 7,4), $1,15 \mathrm{ml} 0,9$ proz. $\mathrm{NaCl}$ $0,05 \mathrm{ml}$ Plasma, 1,0 ml Acetylcholinchlorid von steigender Konzentration, so daß die in der Abszisse angegebenen Endkonzentrationen erreicht werden. Ordinate: Extinktionsabnahme $\triangle E$ (Differenz zwischen Anfangs- und Endwert be einer Inkubationszeit von $20 \mathrm{Min}$.)

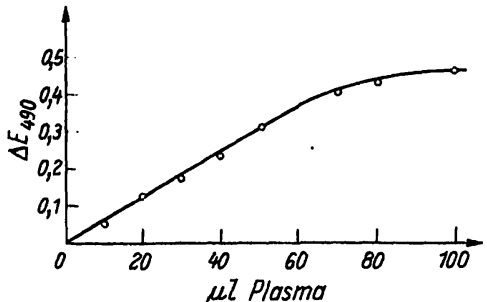

Abb. 3

Beziehung zwischen Substratspaltung und eingesetzter Enzymmenge. Reaktionsbedingungen: $62 \mathrm{~mm}$ Tris (pH 7,4), 2,5 mM Acetylcholin. Plasma entsprechend den in der $A b$ szisse angegebenen Mengen, 0,9 proz. $\mathrm{NaCl}$ ad 3,2 ml. $20 \mathrm{Min}$. Inkubation in Wasserbad bei $37^{\circ}$. Ordinate: Extinktionsabnahme $\Delta \mathrm{E}$ (vg!. Abb. 2)

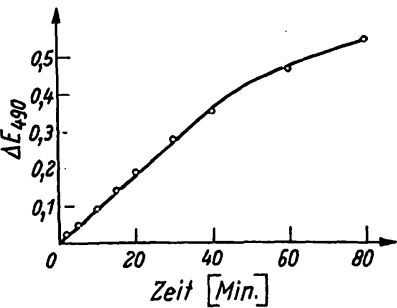

Abb. 4

Abhängigkeit des Substratumsatzes von der Inkubationszeit Reaktionsbedingungen: $1,0 \mathrm{~m} l$ Tris ( $\mathrm{pH} 7,4), 1,15 \mathrm{ml} 0,9$ proz. $\mathrm{NaCl}, 0,05 \mathrm{ml}$ Plasma, Acetylcholin 2,5 ms. Inkubation der Ansätze zwischen 2,5 und 80 Min. bei $37^{\circ} \mathrm{im}$ Wasserbad. Beendigung der Reaktion durch Zugabe von alkalischem Hydroxylamin. Ordinate: Extinktionsabnahme $\triangle E$ (Differenz zwischen Anfangs- u. Endwert) zu der auf der Abszisse angegebenen Inkubationszeit

Substratumsatz wurden $10,25,50,75$ und $100 \mu l$ heparinisiertes Spenderplasma 20 Min. mit Acetylcholin, $\mathrm{NaCl}$ und Tris-Puffer $\mathrm{pH} 7,4$ inkubiert und die Spaltung des Substrates als Extinktionsdifferenz zwischen Anfangsund Endwert angegeben. Die Konzentration an Acetylcholin im Inkubationsansatz war 2,5 mM. Aus der Abbildung geht hervor, daß bis zu einer Plasmamenge von etwa $70 \mu \mathrm{l}$ unter den gewählten Bedingungen eine lineare Zunahme der Substratspaltung mit steigendem Plasmavolumen zu verzeichnen ist. Für die Praxis heißt das, daß auch mit $25 \mu l$ Plasma reproduzierbare Ergebnisse zu erzielen sind. Wir haben dies an mehreren Seren von Patienten überprüft und mit $25 \mu l$ exakt die Hälfte des mit $50 \mu l$ Serum gefundenen Substratumsatzes erhalten. Die in der endgültigen Vorschrift angegebene Substratkonzentration liegt mit 3,0 mM etwas höher als die in der Abbildung verwendete. Es empfiehlt sich aber nicht, mehr als $50 \mu l$ Serum zu verwenden, da sonst bei Zugabe von Hydroxylamin Trübungen auftreten, die regelmäßig zum Filtrieren des Ansatzes zwingen.

In Abbildung 4 ist die Abhängigkeit der Acetylcholinhydrolyse von der Inkubationsdauer dargestellt. Die Konzentration an Acetylcholin betrug hier ebenfalls nur 2,5 mM: Es wurde mit $50 \mu l$ Serum inkubiert und die Reaktion durch Zugabe von alkalischem Hydroxylamin gestoppt. Wie die Abbildung deutlich macht, steigt der Substratumsatz bis zu einer Inkubationsdauer von 40 Min. linear mit der Zeit an. Die für die Routinemethode gewählte Zeit liegt im linearen Umsatzbereich. Wie die Abbildung zeigt, biegt die Kurve dann oberhalb von 40 Min. allmählich ab.

\section{Ergebnisse und Diskussion}

Bei 50 gesunden männlichen und weiblichen Blutspendern wurden Normalwert und Standardabweichung für die angegebene Methode mit Hilfe von Doppelbestimmungen untersucht. Der Mittelwert aller Untersuchungen $(\overline{\mathbf{x}})$ betrug $3467 \mathrm{IU} / l$, die Standardabweichung (s) \pm 602 . Der Normalbereich $(\overline{\mathrm{x}} \pm 2 \mathrm{~s})$ liegt demnach bei 2270 bis $4670 \mathrm{IU} / l$, da es für praktische Bedürfnisse ausreicht, mit einem Mittelwert von $3470 \mathrm{IU} / l$ und einer Streuung von $\pm 600 \mathrm{IU}$ zu rechnen. Diese Werte stim- men gut mit den von WeBER (2) an einem größeren Patientengut mit Acetylthiocholinjodid als Substrat und einer anderen Methode ermittelten Normalwerten überein.

Die beschriebene Methode besitzt trotz ihrer Einfachheit eine gute Zuverlässigkeit. Zu ihrer Überprüfung wurde das Serum eines gesunden Spenders in 10 Parallelbestimmungen am gleichen Tage untersucht, wobei ein Mittelwert von $3060 \mathrm{IU} / l$ bei einem Variationskoeffizienten (v) von 3,2\% ermittelt wurde. Der Variationskoeffizient oder relative Fehler der Methode ist definiert als $\mathrm{v}=\frac{\mathrm{s}}{\overline{\mathrm{x}}} \cdot 100$.

Das Verfahren zeichnet sich bei guter Reproduzierbarkeit der Ergebnisse durch seine große Einfachheit aus, die seine Anwendung auch in jedem kleineren Krankenhaus gestattet, da ein Wasserbad von $37^{\circ}$ und ein Photometer für den sichtbaren Bereich oder ein Kolorimeter allgemein zur Verfügung stehen dürften. Wie Abbildung 2 zeigt, arbeitet das Verfahren bei optimaler Substratkonzentration, die bei $3 \mathrm{~mm}$ liegt und damit deutlich höher ist als bei der von Pilz (9) angegebenen Methode, die eine Substratkonzentration von $1,235 \mathrm{~mm}$ benutzt. Aus der Abbildung 2 ist weiterhin zu entnehmen, daß durch Substratüberschuß in Übereinstimmung mit Untersuchungen von ALLES und Mitarbeitern (10) sowie BrEUER und SCHÖNFELDER (11) im Gegensatz zur Acetylcholinesterase der Erythrocyten das Serumenzym nicht gehemmt wird, während PILZ (12) kürzlich über eine Hemmung der Plasmaacetylcholinesterase durch Substratüberschuß berichtete.

Aus den Abbildungen 3 und 4 geht hervor, daß lineare Proportionalität zwischen Enzymmenge bzw. Inkubationszeit besteht. Das gestattet, die verwendete Serummenge auf $25 \mu \mathrm{l}$ zu reduzieren. Durch das gleichzeitige Mitführen eines Blindwertes wird die Spontanhydrolyse des Substrates bei der Inkubation miterfaßt und eine gesonderte Berechnung im Gegensatz zu anderen Verfahren $(4,6)$ überflüssig. Allerdings ist bei unserer Methode die Spontanhydrolyse des Acetylcholins bei pH 7,4 und $37^{\circ}$ ohnehin praktisch bedeutungslos, wovon wir 
uns in Übereinstimmung mit Pruz (13) in Vorversuchen überzeugen konnten.

Im Gegensatz zu dem von PILz (9) angegebenen Verfahren benutzen wir nur einen Puffer in Form des sehr einfach herzustellenden $0,2 \mathrm{M}$ Tris-Puffers. Des weiteren ist als wesentlicher Vorteil anzusehen, daß bei unserem Verfahren eine Enteiweißung entfällt. Die Reaktion wird durch Zugabe von alkalischem Hydroxylamin gestoppt, wrobei der $\mathrm{pH}$-Wert des Ansatzes auf über 13 ansteigt. Dabei flockt das Protein aus. Mit der Zugabe von $10 \mathrm{~m} l$ bidest. Wasser vor der Ablesung wird ein Gesamtvolumen von $15 \mathrm{ml}$ erreicht, in dem der geringe, $50 \mu l$ Serum entsprechende Proteinniederschlag bei der Ablesung nicht stört. Dies wurde in zahlreichen Parallelbestimmungen einer wäßr. Lösung von Acetylcholin mit und ohne Zusatz von inaktiviertem Serum geprüft. Bei stark getrübten Seren kann vor der Ablesung eine Filtration notwendig werden.

Von Vorteil gegenüber anderen Methoden ist weiterhin die Tatsache, daß der Zeitpunkt für die Ablesung zwischen 30 und $120 \mathrm{Min}$. nach der Zugabe der $\mathrm{FeCl}_{3}$ Lösung gewählt werden kann. Auch nach 24 Stdn. kann noch abgelesen werden, die Werte liegen dann 3-5\% unter denen, die man innerhalb der ersten 2 Stdn. erhäit, was mit den Erfahrungen von PrLz (13) übereinstimmt. Die Angabe einer Zeitspanne von $30 \mathrm{Min}$. nach Zugabe des $\mathrm{FeCl}_{3}$ für die Ablesung stellt ebenfalls nur einen Richtwert dar, da bereits $15 \mathrm{Min}$. nach $\mathrm{FeCl}_{3}$-Zugabe die Reaktion mit Sicherheit abgeschlossen ist.

Abschließend sei darauf verwiesen, daß trotz zahlreicher experimenteller Untersuchungen und klinischer Arbeiten $(1,2,3)$ über den besonderen Wert der Bestimmung der Cholinesteraseaktivität des Serums für die Beurteilung der Leberfunktion nicht nur über die Nomenklatur der Cholinesterasen, sondern auch über ihre physiologische Bedeutung und den Ort ihrer Bildung im menschlichen Organismus erhebliche Unklarheiten bestehen. Dies kommt u. a. in der Tatsache zum Ausdruck, daß in den letzten 20 Jahren zahlreiche sehr unterschiedliche Substrate für die Bestimmung der Cholinesteraseaktivität des Serums verwendet wurden, bei denen es sich häufig gar nicht mehr um Cholinester, sondern um andere aliphatische oder aromatische Carbonsäureester handelt (Übersichten bei Augustinsson (14), HardegG (15), PILz (12)).

Die zahlreichen Substrate und die unterschiedlichen Bezeichnungen für das Serumenzym wie Cholinesterase, Pseudocholinesterase, unspezifische Cholinesterase, daneben "echte" Cholinesterase oder "wahre" Cholinesterase legen die Vermutung nahe, daß es sich bei der Spaltung der Cholinester durch menschliches Serum entweder um die Wirkung eines sehr unspezifischen Enzyms oder um die einer Vielzahl von Enzymen handeln muß. So ist nach HardegG (15) die Verwendung der Bezeichnungen „echte“, „wahre", „spezifische“ oder „unspezifische“ Cholinesterase und „Pseudocholinesterase" auf Grund neuerer Forschungsergebnisse nicht mehr gerechtfertigt, da sie den Tatsachen in keiner Weise Rechnung tragen. Vielmehr sollten die Cholinesterasen auch in Ubereinstimmung mit anderen Untersuchern (4) in 2 Gruppen eingeteilt werden, von denen die Enzyme der ersten Gruppe Acetylcholin schneller als längerkettige Cholinester spalten. Für diese Gruppe, die vorwiegend im Zentralnervensystem, in Muskulatur und Erythrocyten verbreitet ist, wird von der IUB (16) der Trivialname Acetylcholinesterase vorgeschlagen und das Enzym als Acetylcholin-Acetylhydrolase (EC 3.1.1.7) registriert. Die zweite Gruppe von Enzymen spaltet Butyrylcholin schneller als Acetylcholin und kommt vorwiegend in Leber, Darm und Plasma vor. Dieses Enzym wird von der IUB (16) unter dem Trivialnamen Cholinesterase als Acylcholin-Acylhydrolase (EC 3.1.1.8) registriert. Allerdings ist auch diese Einteilung willkürlich. Die Übergänge zwischen beiden Gruppen cholinesterspalte hider Fermente sind fließend, so daß eine zu strenge Tirennung nicht sinnvoll erscheint.

Während früher überwiegend die Meinung vertreten wưrde, daß im Serum keine ,echte" Acetylcholinesterase existiert, konnte kürzlich PILz (17) die Existenz von 2 Enzymen im menschlichen Serum nachweisen, die spezifisch Acetylcholin und keine anderen Substrate spalten. Als Ursprungsort der Cholinesterasen des menschlichen Serums wird von den meisten Autoren $(2,3,18$ u. a.) die Leber genannt, wobei jedoch viele diese Meinung von anderen. Untersuchern übernehmen. Es ist in diesem Zusammenhang interessant, $\mathrm{da} B$ es in neueren Untersuchungen (12) nicht gelang, eine Acetylcholinspaltung durch Homogenate aus menschlicher Leber nachzuweisen. Neben den bereits erwähnten $(3,18)$ klinischen Beobachtungen und anderen Methoden, die zur Beurteilung der Leberfunktion die Acetylcholinspaltung des Serums verwenden, sowie eigenen Erfahrungen bei Patienten mit Leberparenchymschäden, scheinen die gute Korrelation, die von zahlreichen Untersuchern $(18,19,20)$ zwischen dem „Achol“-Test, einem Testpapier, das mit Acetylcholin als Substrat getränkt ist $(6,18)$, und mit anderen Substraten und Methoden gewonnene Ergebnisse für eine Bildung auch der Acetylcholinesterase in der Leber zu sprechen. Auf Grund der vorliegenden methodischen Mitteilung kann zu dieser Frage allerdings nicht Stellung genommen werden.

\section{Literatur}

1. Doenicke, A. und S. Schmidinger, Med. Klinik 60, 2012 (1965). 2. WEBER, H., Dtsch. med. Wschr. 91,1927 (1966). - 3. a) DreCKHOFF, J. und U. WIEGAND, Dtsch. Gesd.wes. 21, 305 (1966). - b) Dieckhoff, J. und U. Wiegand, Pädiatr. und Grenzgeb. 5, 141 (1966). - 4. Bockendahr, H. und R. Ammon, in Methoden der enzymatischen Analyse S. 771, hrsg. H.-U. Bergmeyer, Verlag
Chemie, Weinheim/Bergstr. (1962). - 5. Kalow, W. und H. A. Lindsay, Canad. J. Biochem. 33, 568 (1955). - 6. MeINECKE, K. H. und H. Oetrele, Arch. Toxikol. 21; 321 (1966). - 7: Hestrin, S., J. biol. Chemistry 180, 249 (1949). - 8. Pilz, W., Z. analyt. Chem. 162, 81 (1958). - 9. Pilz, W., I. Johann und E. StelzL, Klin. Wschr. 43, 1227 (1965). - 10. Alles, G. A. und 
R. C. Hawes, J. biol. Chemistry 133, 375 (1944). - 11. Breuer, H. und M. Schönfelder, Clin. chim. Acta, Amsterdam 6, 515 (1961). 12. Pilz, W., diese Z. 5, 1 (1967). - 13. Pilz, W. und I. JohanN, diese Z. 4, 215 (1966). - 14. Augustinsson, K.-B., Meth. biochem. Analysis 5, 1 (1957). - 15. HardegG, W., in Hoppe-Seyler/Thierfelder: Handbuch der physiologisch- und pathologisch-chemischen Analyse, Bd. VI/B, S. 921, 10. Aufl., Springer Berlin (1966). - 16.
Report of the Commission on Enzymes of the International Union of Biochemistry, Pergamon Press, Oxford, London; New York, Paris 1961. - 17. Przz, W., Hoppe-Seyler's Z. physiol. Chem. 345, 80 (1966). - 18. Härtel, A., W. Gross und H. LANG, diese Z. 5, 26 (1967). - 19. Schmidinger, St. und A. Doenicke, diese Z. 4, 273 (1966). - 20. Thompson, J. C. und M. WhitTAKeR, J. Clin. Path. London 18, 811 (1965).
Dr. H. Willgerodt $X 705$ Leipzig Oststraßc. $21-25$

\title{
Erfahrungen mit einer kolorimetrischen Methode zur Bestimmung der nicht veresterten Fettsäuren im Serum ${ }^{1}$ )
}

\author{
Von P. Dieterle, C. Wülfert-Heldrich, J. Henner und K. Schwarz \\ Aus der II. Medizinischen Klinik der Universität München (Direktor: Prof. Dr. Dr. G. Bodecbtel)
}

(Eingegangen am 26. Januar 1968)

Es wird über eigene Erfahrungen mit der kolorimetrischen Bestimmung der NFS nach DuNcombE $(6,7)$ berichtet. Es besteht eine gute Korrelation beim Vergleich des beschriebenen Verfahrens mit der Titrationsmethode nach DoLE $(1,2)$. Die Vorteile der Methode werden besprochen.

Studies are reported on the colorimetric determination of nonesterified fatty acids according to DuncomBE $(6,7)$. There is good correlation between the described method and the titration method of Dole $(1,2)$. The advantages of the methods are discussed.

Eine in der klinischen Medizin gebräuchliche Bestimmungsmethode ist die Messung der nicht veresterten Fettsäuren $(\mathrm{NFS})^{2}$ ) im Serum mit dem Titrationsverfahren nach DoLE bzw. Dole und MEINERTz $(1,2)$. Trotz guter Reproduzierbarkeit ist diese Methode nicht ganz frei von Nachteilen. Ein anderes Verfahren zur Bestimmung der NFS mittels Kolorimetrie hat 1956 Ayers (3) mitgeteilt, das 1959 von Iwayama (4) und 1961 von BARRETO und MaNo (5) weiter modifiziert wurde. Von Duncombe $(6,7)$ wurde schließlich die Methode in ihrer Empfindlichkeit so verbessert, $\mathrm{da} ß$ sie sich gut für klinische und biochemische Fragestellungen eignet. Unsere Erfahrungen mit dieser kolorimetrischen Methode und die Vorteile gegenüber dem Titrationsverfahren sollen in dieser Arbeit anhand vergleichender Untersuchungsreihen herausge-stellt und beurteilt werden.

\section{Methodik}

Prinzip

Die NFS werden als Kupfersalze mit Chloroform extrahiert. Die Kupferseifen werden mit Diäthyldithiocarbaminat in einen Kupferkomplex überführt und kolorimetrisch bestimmt.

\section{Reagenzien}

1. Chloroform p. a.

2. Kupferreagenz:

a) $\mathrm{Cu}\left(\mathrm{NO}_{3}\right)_{2} \cdot 3 \mathrm{H}_{2} \mathrm{O}, 6,45$ proz. Lösung,

b) 9 Teile $1 \mathrm{M}$ Triäthanolamin +1 Teil 1N Essigsäure a) und b) werden im Verhältnis 1:1 gemischt.

3. Natrium-Diäthyldithiocarbaminat $\left(\mathrm{C}_{5} \mathrm{H}_{10} \mathrm{~N} \mathrm{NaS} \cdot 3 \mathrm{H}_{2} \mathrm{O}\right)$. Es wird eine 0,1proz. Lösung in sek. Butanol hergestellt.

Lösung 2 und 3 müssen im Kühlschrank aufbewahrt und jede Woche erneuert werden.

1) Mit Unterstützung der Deutschen Forschungsgemeinschaft.

2) Abktirzungen: NFS = nicht veresterte Fettsäuren.

\section{Durchfiibrung}

In ein geschliffenes Reagenzglas werden $5 \mathrm{~m} /$ Chloroform (bzw. in $5 \mathrm{ml}$ gelöster Palmitinsäurestandard), $2,5 \mathrm{~m} /$ Kupferreagenz und $0,5 \mathrm{ml}$ Serum pipettiert. Nach sorgfältigem Verschluß der Schliffgläser (wir verwenden dafür lipoidunlösliche Kunststoffstopfen) wird das Gemisch in einer dreidimensionalen Schüttelapparatur $30 \mathrm{Min}$. gleichmäßig geschüttelt. Anschließend wird das Gemisch $15 \mathrm{Min}$. bei 2000 bis $3000 \mathrm{~g}$ zentrifugiert. Es bilden sich 2 Phasen. Die obere wäßr. Phase mit dem überschüssigen Kupferreagenz ist von der unteren Chloroformphase durch eine ausgefällte Eiweißschicht getrennt. Mit einer an die Wasserstrahlpumpe angeschlossenen Kapillare wird nun einschließlich der an der Glaswandung haftenden Tropfen die obere Kupferphase und anschließend vorsichtig die Eiweißschicht abgesaugt. Vom Chloroformrückstand werden sofort $3 \mathrm{~m} /$ in ein kleines Schliffglas abpipettiert. Dabei ist sorgfältig darauf zu achten, daß die Pipette nicht die Glaswandung berührt und damit Kupfer überträgt. Zur Chloroformphase werden $0,5 \mathrm{~m} /$ 'der Diäthyldithiocarbaminatlösung gegeben und der gelbgefärbte Kupferkomplex bei $436 \mathrm{~nm}$ (Photometer Eppendorf) gegen einen Reagenzienblindwert, der durch die gesamte Messung mitläuft, innerhalb einer Stunde gemessen.

Die Berechnung erfolgt nach der Formel

Extinktion Probe $\cdot \frac{\mu \mathrm{Val} / / \text { des Standards }}{\text { Extinktion Standard }} \cdot 10=\mu \mathrm{Val}$ NFS $/ /$ Serum

Diskussion der Methode

Bestimmungen von reinen Palmitinsäurelösungen zeigen, daß zwischen der Konzentration und der Extinktion strenge Proportionalität besteht (Abb. 1). Es genügt daher im allgemeinen, nur einen Palmitinsäurestandard mitlaufen zu lassen. In weiteren Versuchen wurde Natriumpalmitat an Serumalbumin gebunden und anschließend die Wiederfinderate bestimmt. Im Mittel wurden $98 \%$ des eingesetzten Palmitat-Standards wiedergefunden. Dies stimmt mit Angaben von ITAYA und UI (8) überein. Die geringere Wiederfindequote von Duncombe (7) führen wir auf 